\title{
Genetic differences in periovum sensitivity to hyaluronidase and protease between C57BL/6, BALB and CXB recombinant mice*
}

\author{
S. A. A. Bander, S. C. Watson $\dagger$ and J. G. M. Shire \\ Department of Biology, University of Essex, Colchester CO4 3SQ, U.K.
}

\begin{abstract}
Summary. The cumulus oophorus surrounding eggs from C57BL/6 mice was digested by bovine or leech hyaluronidase significantly more rapidly than that surrounding eggs from $\mathrm{BALB} / \mathrm{c}$ mice. The zona pellucida of $\mathrm{C} 57 \mathrm{BL} / 6$ eggs was also more rapidly attacked by pronase. Three other sublines of C57BL showed the same characteristics. Measurements of susceptibility to hyaluronidase and pronase on eggs from the CXB recombinant inbred strains indicated that variation at a minimum of 2 loci affected each character. The lack of correlation between susceptibilities to the 2 enzymes across the recombinant strains implied that these differences separately affect the substrates of the enzymes, rather than reflecting a common difference in the process of oocyte maturation. The variation in susceptibility was unrelated to differences, controlled by the Ped and $Q a-2$ loci, in the rate of later embryonic cleavage. However, pronase susceptibility was significantly correlated with the early onset of the first cleavage.
\end{abstract}

Keywords: cumulus; zona pellucida; inbred strains; fertilization; cleavage; mouse

\section{Introduction}

Preimplantation development proceeds faster in some strains of mice than in others. C57BL mice develop rapidly in the early cleavage stages (Dickson, 1967; McLaren \& Bowman, 1973; Niwa et al., 1980; Shire \& Whitten, 1980a; Goldbard \& Warner, 1982). They also belong to the group of strains having the largest number of cells at the time that fast developing strains form blastocysts (89 h after hCG: Warner et al., 1988). Observations in vivo (McLaren \& Bowman, 1973) suggested that cleavage started earlier in C57BL zygotes than in those of several other strains. This was confirmed by in-vitro studies in which first cleavage was shown to take place $4 \mathrm{~h}$ earlier in C57BL/6By than in BALB/cBy mice (Shire \& Whitten, 1980a). Whitten \& Dagg (1961) proposed that the time of cleavage is determined by the timing of fertilization. In C57BL mice mating is reported to be early, as is the arrival of spermatozoa in the vicinity of the ova (Braden, 1958; Nicol \& McLaren, 1974). Early fertilization would also be aided by rapid penetration of the ova by spermatozoa (McLaren \& Bowman, 1973). This would be in accord with reports that the cumulus oophorus of eggs from C57BL/Fa (Braden, 1958), C57BL/Kw (Krzanowska, 1972), C57BL/6J (Erickson \& Krzanowska, 1974) and C57BL/BiMcL (Nicol \& McLaren, 1974) mice were all relatively sensitive to digestion by hyaluronidase. Consequently, we have investigated the genetic basis of sensitivity of the periovum layers to enzymic attack. We have used C57BL/6ByEss and BALB/ cByEss mice as representatives of fast and slowly developing strains, in terms both of first cleavage (Shire \& Whitten, 1980a) and subsequent developmental rate (Warner et al., 1988). This paper

\footnotetext{
*Reprint requests to Professor J. G. M. Shire.

†Present address: ICI Central Toxicology Laboratory, Alderley Park, Macclesfield SL10 4TJ, U.K.
} 
describes the susceptibility of the cumulus oophorus and the zona pellucida of eggs from these strains and also from those of the 7 CXB recombinant-inbred strains derived from them (Bailey, 1971).

Each recombinant inbred strain provides a repeatable, homozygous, sample of a particular recombination (haplotype) of the various separable genetic differences between the parental strains. This is not the case for segregating $F_{2}$ and backcross generations in which every individual has a unique genotype and cannot be pooled with others for the analysis of developmental characters. Use of the recombinant inbred mice allowed us to examine the apparent positive correlation found in the parental strains for susceptibility to digestion of periovum layers and to analyse the relationship of these susceptibilities to known differences in the timing of the first and later cell divisions in development.

\section{Materials and Methods}

Eggs were obtained for analysis from adult female mice, aged 10.7 \pm 0.7 weeks, bred at the University of Essex. The females were from the C57BL/6ByEss and BALB/cByEss inbred strains and from the CXBD/ByEss, CXBE/ByEss, CXBG/ByEss, CXBH/ByEss, CXBI/ByEss, CXBJ/ByEss and CXBK/ByEss recombinant inbred strains. These recombinant inbred strains are referred to as $\mathrm{D}, \mathrm{E}, \mathrm{G}, \mathrm{H}, \mathbf{I}, \mathbf{J}$ and $\mathrm{K}$. In addition, eggs were obtained from mice of the C57BL/10ScSnLac subline, from a congenic subline segregating for albino (B10.c) and from a subline segregating for the mutation reduced pigmentation (B10.rp), whose genotype was at least $15 / 16 \mathrm{C} 57 \mathrm{BL} / 10 \mathrm{ScSn}$ with the remainder C57BL/Tb. Details of the two congenic lines are given in Gibb et al. (1981) and Ahmed \& Shire (1985). All mice were raised under standard environmental conditions, as described by Janat \& Shire (1987), except that sieved sawdust bedding (grade 18, Sawdust Manufacturing Co., Standon, Herts) was provided.

Ovulation was induced by the i.p. injection of 8 i.u. PMSG (Sigma Chemical Co., St Louis, MO, U.S.A) at 16:00 h, $3 \mathrm{~h}$ before dark, and, $48 \mathrm{~h}$ later, 8 i.u. hCG (Boehringer-Mannheim Gmbh, Mannheim, F.R.G.). Eggs in cumulus were normally removed from the oviducts $18 \mathrm{~h}$ after hCG. One set of observations was made on eggs $12 \mathrm{~h}$ after hCG. The eggs in cumulus from a single oviduct were transferred to $0.5 \mathrm{ml}$ phosphate-buffered saline $(0.15 \mathrm{M}, \mathrm{pH} 7 \cdot 2)$ containing bovine testicular hyaluronidase (Sigma) and observed every minute until all the eggs were free of cumulus cells. One set of observations was made using hyaluronidase from leeches (Orgelase: Calbiochem, La Jolla, CA, U.S.A.). These eggs were then transferred to $0.5 \mathrm{ml}$ phosphate-buffered saline containing pronase (Boehringer-Mannheim) and observed every minute until all eggs had lost their zona pellucida. Preliminary experiments (Watson, 1983a) were carried out at ambient temperature, with 12 i.u. hyaluronidase followed by 15 i.u. pronase. Subsequently, incubations were carried out at $37^{\circ} \mathrm{C}$, using a thermostatically regulated microscope stage. Enzyme levels were standardized at 12 i.u. hyaluronidase and 5 i.u. pronase, after experiments with 25 i.u. hyaluronidase and 10 and $2 \cdot 5$ i.u. pronase.

All observations were made on clutches of at least 6 eggs from the same oviduct. A preliminary analysis of variance on mice of 9 genotypes showed that within-mouse variation did not contribute significantly more to the variance than did mouse-to-mouse differences within genotypes. Consequently, the separate measurements on the clutches from the left and right oviducts of each animal were used in subsequent analyses. The median dissolution time was calculated for each clutch of eggs for each enzyme treatment. The mean and standard error of the median dissolution time were calculated for each treatment for each genotype. Analysis of variance and $t$ tests were carried out using the SPSS statistical package (Nie et al., 1975). Correlations were analysed both parametrically and non-parametrically (Spearman Rank Correlation).

\section{Results}

Preliminary experiments showed that eggs from C57BL/6ByEss mice were freed of cumulus more quickly than those of BALB/cBy mice. The optimum amount of hyaluronidase was found to be $12 \mathrm{i}$.u. Table 1 shows the means of the median time to disperse the cumulus at $37^{\circ} \mathrm{C}$ in the two parental strains, 3 other $\mathrm{C} 57 \mathrm{BL} / \mathrm{BL}$ sublines and the 7 recombinant inbred strains. Analysis of variance showed a significant effect of genotype on dispersion time $\left(\mathrm{F}_{11,237}=964, P \ll 0.001\right)$. The cumulus surrounding BALB eggs took significantly longer $(10.4 \mathrm{~min}, t=22, P<0.001)$ to disperse than did that surrounding C57BL/6ByEss eggs. The cumulus of eggs from all 4 sublines of C57BL dispersed rapidly (mean times, $19.7-23.9 \mathrm{~min}$ ). Of the recombinant inbred strains, D was identical to C57BL and $\mathrm{H}$ and $\mathrm{K}$ both closely resembled BALB. Eggs from the G, E, I and $J$ lines were significantly less susceptible to hyaluronidase than were eggs from either parental strain. 
The zona pellucida of eggs from C57BL/6ByEss mice was digested more rapidly than that of eggs from the BALB mice by both 5 i.u. ( $4.1 \mathrm{~min}, t=6.6, P<0.001)$ and 2.5 i.u. $(6.6 \mathrm{~min}, t=11$, $P<0.001)$ pronase added to the medium. The results in Table 1 show significant effects of genotype on responses to $5 \mathrm{i} . \mathrm{u}$. pronase $\left(\mathrm{F}_{1.200}=174, P \ll 0.001\right)$. Two of the recombinant inbred strains ( $\mathrm{I}$ and $\mathrm{H}$ ) were significantly more susceptible than the C57BL mice. The eggs from the 4 C57BL sublines were similar in their susceptibility to pronase $(13.3,13.5,13.5$, and $14.9 \mathrm{~min})$. The mean of the $\mathrm{D}$ line, as for hyaluronidase, fell within the range of the C57BL values while the $\mathrm{G}$ mice resembled their BALB parental strain. Three recombinant strains, E, K and J, were significantly more resistant to pronase than were either of their progenitor strains.

Table 2 shows the mean responses of eggs from the parental strains when exposed sequentially to bovine hyaluronidase and pronase $12 \mathrm{~h}$ after the injection of $\mathrm{hCG}$. The eggs from $\mathrm{C} 57 \mathrm{BL} /$ 6ByEss mice were significantly more susceptible to both enzymes than were eggs from BALB mice at this time, and the differences between the two strains were more marked than at $18 \mathrm{~h}$ after hCG. Incubation with leech hyaluronidase also showed the cumulus of eggs from the two strains to be different.

Table 1. Median times for hyaluronidase to disperse the cumulus oophorus and for pronase digestion of the zona pellucida of clutches of eggs from mice of 12 genotypes

\begin{tabular}{lcc}
\hline Strain & $\begin{array}{c}\text { Dispersion time } \\
\text { with hyaluronidase } \\
\text { (min) }\end{array}$ & $\begin{array}{c}\text { Digestion time } \\
\text { with pronase } \\
\text { (min) }\end{array}$ \\
\hline BALB/cByEss & $31.2 \pm 0.3(28)$ & $17.6 \pm 0.4(20)$ \\
C57BL/6ByEss & $20.8 \pm 0.3(18)$ & $13.5 \pm 0.5(17)$ \\
C57BL/10ScSn & $22 \cdot 1 \pm 0.3(26)$ & $13.5 \pm 0.3(24)$ \\
B10.c & $23.9 \pm 0.4(17)$ & $13.3 \pm 0.3(13)$ \\
B10.rp & $19.7 \pm 0.3(21)$ & $14.9 \pm 0.3(20)$ \\
CXBD & $21 \cdot 2 \pm 0.2(26)$ & $14.5 \pm 0.4(23)$ \\
CXBE & $46.8 \pm 0.4(19)$ & $21.9 \pm 0.4(17)$ \\
CXBG & $44.6 \pm 0.4(18)$ & $17.9 \pm 0.4(16)$ \\
CXBH & $29.7 \pm 0.2(18)$ & $9.4 \pm 0.2(15)$ \\
CXBI & $50.2 \pm 0.4(15)$ & $7.1 \pm 0.3(11)$ \\
CXBJ & $51.4 \pm 0.5(23)$ & $26.8 \pm 0.5(19)$ \\
CXBK & $33.1 \pm 0.5(21)$ & $22.0 \pm 0.4(18)$ \\
\hline
\end{tabular}

Values are mean \pm s.e. for the no. of clutches in parentheses.

Table 2. Median times for enzymic dissolution by pronase and bovine hyaluronidase of periovum layers $12 \mathrm{~h}$ after hCG, together with the median time for dissolution by leech hyaluronidase $18 \mathrm{~h}$ after $\mathrm{hCG}$

\begin{tabular}{|c|c|c|c|}
\hline & \multicolumn{2}{|c|}{$12 \mathrm{~h}$ after hCG } & \multirow{2}{*}{$\begin{array}{c}18 \mathrm{~h} \text { after } \mathrm{hCG} \\
\begin{array}{c}\text { Leech } \\
\text { hyaluronidase } \\
(\mathrm{min})\end{array}\end{array}$} \\
\hline & $\begin{array}{l}\text { Pronase } \\
\text { (min) }\end{array}$ & $\begin{array}{c}\text { Bovine } \\
\text { hyaluronidase } \\
\text { (min) }\end{array}$ & \\
\hline C57BL/6ByEss & $14 \cdot 9 \pm 0 \cdot 3(18)$ & $23 \cdot 3 \pm 0 \cdot 3(22)$ & $17 \cdot 2 \pm 0 \cdot 3(20)$ \\
\hline BALB/cByEss & $22.7 \pm 0.5(25)$ & $38.5 \pm 0.5(28)$ & $22.7 \pm 0.3(22)$ \\
\hline$t$ & 12 & 24 & 12 \\
\hline Probability & $<0.001$ & $<0.001$ & $<0.001$ \\
\hline
\end{tabular}

Values are mean \pm s.e. for the no. of clutches in parentheses. 


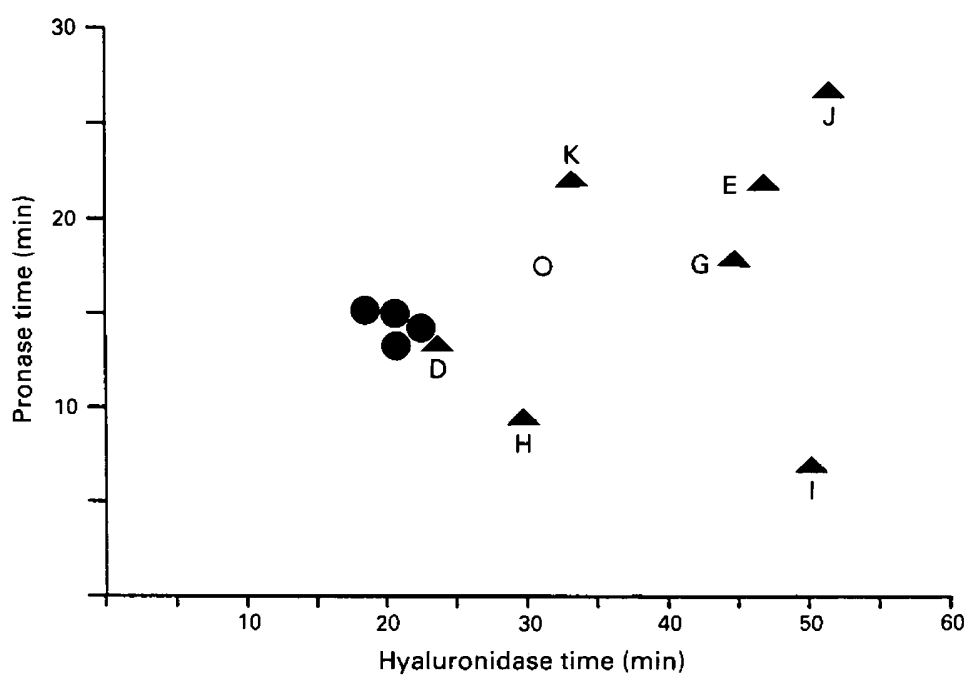

Fig. 1. Relationship between mean susceptibilities to hyaluronidase and pronase for eggs from mice of 12 genotypes. BALB is shown by $O$, the 4 C57BL sublines by and the recombinant inbred strains by $\boldsymbol{\Delta}$.

\section{Discussion}

Our observations confirm that the cumulus oophorus of eggs from C57BL mice is more easily digested by bovine hyaluronidase, and show that the cumulus of eggs of BALB mice is more resistant both around the usual time of fertilization ( $12 \mathrm{~h}$ after $\mathrm{hCG}$ ) and at $18 \mathrm{~h}$ after $\mathrm{hCG}$. The similarity of effects of leech hyaluronidase, an endo $\beta$-glucuronidase that only attacks hyaluronic acid (Yuki \& Fishman, 1963), to those of bovine hyaluronidase, an endo $\alpha$-acetyl hexose aminidase that also cleaves chondroitin and chondroitin 4- and 6-sulphates, indicates that the integrity of the cumulus is maintained by hyaluronic acid.

The zona pellucida surrounding C57BL eggs, for all 4 sublines examined, is more easily digested away than that surrounding BALB/cByEss eggs. Previous reports have shown that $\mathrm{C} 57 \mathrm{BL} / \mathrm{Kw}$ and $\mathrm{CBA} / \mathrm{Kw}$ eggs are equally susceptible to pronase and trypsin and less resistant than those of $\mathrm{KE} / \mathrm{Kw}$ mice (Krzanowska, 1972) and that eggs from C57BL/Kw mice are less susceptible to chymotrypsin than those of DDK mice but more susceptible than eggs from $\mathrm{C} 3 \mathrm{H} / \mathrm{Kw}$ mice (Wabik-Sliz, 1985).

The occurrence in the recombinant inbred strains of 3 phenotypes for hyaluronidase responsiveness and 4 for pronase susceptibility indicates at least 2 loci for each trait. However, the recovery of recombinant inbreds resembling each parent in a sample of only 7 implies that the number of loci involved is not large, at least for the difference between C57BL and BALB. This is reinforced by the finding that the $\mathrm{D}$ line resembles its C57BL parent in susceptibility to both enzymes and that the cumulus dispersion time for eggs from $\mathrm{D} \times \mathrm{C} 57 \mathrm{BL}$ and $\mathrm{C} 57 \mathrm{BL} \times \mathrm{D} F 1$ hybrids were very similar to each other $(19.1 \pm 0.3 \mathrm{~min}, n=13$, and $20.7 \pm 0.3 \mathrm{~min}, n=27)$ and to the values for eggs from C57BL/6ByEss and CXBD/ByEss (20.7 and 21.2 min; Table 1). Similarly, the mean times required for pronase to digest the zona pellucida of these F1 eggs $(14 \cdot 1 \pm 0.5 \mathrm{~min}, n=25,14.7 \pm 0.5 \mathrm{~min}, n=12)$ were very similar to those for the C57 and D parental strains (13.5 and $14.5 \mathrm{~min}$; Table 1).

The relationship between susceptibility of eggs to the 2 enzymes is shown in Fig. 1 for the 12 genotypes. Although the two characters appear correlated in the C57BL and BALB progenitor strains this correlation breaks down $(r=0 \cdot 32$, NS) when the data for the 7 recombinant lines are included. This is particularly striking for CXBI, which is one of the genotypes most resistant to 
hyaluronidase yet is the one most sensitive to pronase. The genetic systems underlying the differences in susceptibility to the 2 enzymes must therefore be different, suggesting that the differences lie in the substrates for the 2 enzymes (mucopolysaccharides and proteins respectively) rather than in a common difference affecting the rate of maturation of the oocyte investments. Initial differences have been found between the two strains in the pattern revealed by polyacrylamide gel electrophoresis of the proteins from cumulus cells (Watson, 1983b). Investigations of strain differences in the major ZP proteins (Wasserman et al., 1986; Ringuette et al., 1986) and other constituents of the zona pellucida might be rewarding. That the arrangement of genes found in the 2 long-established inbred strains is not entirely due to chance is suggested by the observation that the investments of eggs of mice of the DDK strain are even more susceptible to both enzymes than are those of C57BL eggs (Wabik-Sliz, 1985).

The differences between the C57BL and BALB/cBy strains in the rate of later cleavage, controlled by the Ped and Qa-2 genes (Warner et al., 1988), are not related to the differences in susceptibility of the eggs to either enzyme. Of the recombinant inbred lines only $\mathrm{D}$ and $\mathrm{H}$ have the $H-2^{\text {d }}$ haplotype associated with slow late development yet $\mathrm{D}$ eggs were susceptible to both enzymes whilst $\mathrm{H}$ eggs resembled BALB in their resistance to hyaluronidase and C57BL in their susceptibility to pronase. The variation in hyaluronidase sensitivity is unrelated $\left(r_{\mathrm{s}}=0.09, r=0.03 \mathrm{NS}\right)$ to the variation in the time of first cleavage found in mice of the C57BL and BALB strains and their recombinant inbred derivatives (Shire \& Whitten, 1980a), even though C57BL is susceptible and cleaves early whilst BALB is more resistant and cleaves later. However, susceptibility to pronase digestion is significantly correlated $\left(r_{\mathrm{s}}=0.68, r=0.72, P<0.02\right)$ with earliness of first cleavage in these 9 mouse genotypes. CXBI mice combine very early cleavage with maximum susceptibility while CXBJ eggs show maximum resistance to pronase, divide last and showed a significant rate of failure to complete blastocyst formation (Shire \& Whitten, 1980a). Differences in the zona pellucida may therefore be related to differences in the ease and promptness of its penetration by spermatozoa, and consequently in the timing of the start of the cleavage process, and the time of occurrence of the first cell division. Control of the rate of events in the more rapid cell divisions that follow would appear to pass to the Qa-2 system (Warner et al., 1988).

It will be of interest to analyse the relationship of the differences described here in the characteristics of eggs to differences in fertilization and the initiation of development contributed by the spermatozoa and the male parent (Braden, 1958; Shire \& Whitten, 1980b; Tarter \& Alexander, 1984).

We thank Sheila Bareham and David Spayne for careful technical assistance. S.A.A.B. acknowledges a scholarship from the Higher Education Grant Committee, Sudan.

\section{References}

Ahmed, F. \& Shire, J.G.M. (1985) Lysosomal mutations inhibit lipofuscinosis of the spleen in C57BL mice. $J$. Hered. 76. 311-312.

Bailey, D.W. (1971) Recombinant inbred strains: An aid to finding identity, linkage and function of histocompatibility and other genes. Transplantation 11, 325-327.

Braden, A.W.H. (1958) Variation between strains of mice in phenomena associated with sperm penetration and fertilization. J. Genet. 56, 37-47.

Dickson, A.D. (1967) Variations in development of mouse blastocysts. J. Anat. 101, 263-267.

Erickson, R.P. \& Krzanowska, H. (1974) Differences in hyaluronidase activities among inbred strains of mice and their possible significance for variation in fertility. J. Reprod. Fert. 39, 101-104.
Gibb, S., Håkansson, E.M., Lundin, L.-G. \& Shire, J.G.M. (1981) Reduced pigmentation ( $r p$ ), a new coat colour gene with effects on kidney lysosomal glycosidases in the mouse. Genet. Res. 37, 95-103.

Goldbard, S.B. \& Warner, C.M. (1982) Genes affect timing of early mouse embryo development. Biol. Reprod. 27, 419-424.

Janat, F.M. \& Shire, J.G.M. (1987) The adrenal X-zone of mice: genetic analysis of its development with recombinant-inbred strains. Expl Biol. 46, 217-222.

Krzanowska, H. (1972) Rapidity of removal in vitro of the cumulus oophorus and the zona pellucida in different strains of mice. J. Reprod. Fert. 31, 7-14.

McLaren, A. \& Bowman, P. (1973) Genetic effects on the timing of early development in the mouse. $J$. Embryol. exp. Morph. 30, 491-498. 
Nicol, A. \& McLaren, A. (1974) An effect of the female genotype on sperm transport in mice. J. Reprod. Fert. 39, $421-424$.

Nie, N.H., Hull, C.H., Jenkins, J.G., Steinbrenner, K. \& Bent, D.H. (1975) Statistical Package for the Social Sciences, 2nd edn. McGraw-Hill, New York.

Niwa, K., Araki, M. \& Iritani, A. (1980) Fertilization in vitro of eggs and first cleavage of embryos in different strains of mice. Biol. Reprod. 22, 1155-1159.

Ringuette, M.J., Sobieski, D.A., Chamow, S.M. \& Dean, J. (1986) Oocyte-specific gene expression: Molecular characterization of a cDNA coding for ZP-3, the sperm receptor of the mouse zona pellucida. Proc. natn. Acad. Sci. U.S.A. 83, 4341-4345.

Shire, J.G.M. \& Whitten, W.K. (1980a) Genetic variation in the timing of first cleavage in mice: effect of maternal genotype. Biol. Reprod. 23, 369-376.

Shire, J.G.M. \& Whitten, W.K. (1980b) Genetic variation in the timing of first cleavage: effect of paternal genotype. Biol. Reprod. 23, 363-368.

Tarter, T.H. \& Alexander, N.J. (1984) Genetic control of humoral immunity to sperm acrosomal and cell surface antigens. J. Reprod. Immunol. 6, 213-226.

Wabik-Sliz, B. (1985) Dispersion of cumulus oophorus and dissolution of the zona pellucida in oocytes of the DDK and other strains of mice. Gamete Res. 11, 391-398.
Warner, C.M., Brownell, M.S. \& Dewoldsen M.A. (1988) Why aren't embryos immunologically rejected by their mothers? Biol. Reprod. 38, 17-29.

Wasserman, P., Bleil, J.D., Florman, H.M., Greve, J.M., Roller, R.J. \& Salzmann, G.S. (1986) Nature of the mouse egg's receptor for sperm. In the Molecular and Cellular Biology of Fertilisation, pp. 55-77. Ed. J. L. Hedrick. Plenum Press, New York.

Watson, S.C. (1983a) Genetic differences in the responses of zona pellucida and cumulus oophorus to hyaluronidase and pronase. Genet. Res. 41, 309, Abstr.

Watson, S.C. (1983b) The response of mouse zonae pellucidae and cumuli oophori to enzymes. M.Sc. thesis, University of Essex.

Whitten, W.K. \& Dagg, C.P. (1961) Influence of spermatozoa on cleavage rate of mouse eggs. J. exp. Zool. 148, 173-183.

Yuki, H. \& Fishman, W.H. (1963) Purification and characterization of leech hyaluronic acid endo- $\beta$ glucuronidase. J. biol. Chem. 238, 1877-1879.

Received 19 May 1988 